\title{
Axillary Disorder
}

National Cancer Institute

\section{Source}

National Cancer Institute. Axillary Disorder. NCI Thesaurus. Code C35746.

A non-neoplastic or neoplastic disorder that affects the structures of the axilla.

Representative examples include axillary lymphadenitis, axillary lipoma, and metastatic carcinoma to the axillary lymph nodes. 